\title{
LXV. Observations respecting the natural production of saltpetre on the walls of subterraneous and other buildings
}

\author{
John Kidd M.D. \& William Hyde Wollaston M.D. Sec.R.S.
}

To cite this article: John Kidd M.D. \& William Hyde Wollaston M.D. Sec.R.S. (1814) LXV. Observations respecting the natural production of saltpetre on the walls of subterraneous and other buildings, Philosophical Magazine Series 1, 44:200, 415-427, DOI: $10.1080 / 14786441408637480$

To link to this article: http://dx.doi.org/10.1080/14786441408637480

曲 Published online: 27 Jul 2009.

Submit your article to this journal $\pi$

Ш Article views: 2

View related articles $\sqsubset$ 
the same method of analysis, I found in the very violet precipitate obtained by using an exeess of muriate of tin, oxide of tin 60.18 , and gold $39 \cdot 82$; and in precipitate of a fue purple, made with excess of muriate of gold, I found oxite of tin 20.58 , and grold $79 \cdot 42$.

From these experiments it results that prccipitates by muriate of tin are very variable, since, when the solutions are concentrated, the gold is always thrown down in the metallic state; and that, when the solutions are diluted, the difference in their proportions oceasions precipitates equally variable in their composition and properties. In what state is the gold found in them ? It is difficult to answer this question; but every thing tends to show, that if it is not entirely in a metallic state, as l'roust thinks, there can remain in it only a minute proportion of oxygen.

L.XV. Observations respecting the natural Production of Saltpetre on the Walls of sullerraneous and other Buildings. By JoHn Kidi, M.D. Professor of Chemistry at Oxfort. Communicated by William Hyde Wollaston, M.D. Sec. R.S.*

A Although the following observations afford no positive evidence of the source of that saline eflilorescence which is so frequently seen on the walls of subterraneous and other buildings, and which, as consisting principally if not entirely of common nitre, long since gave rise to the name + by which that salt is most commonly known; yet as tending to throw some light on a very obscure part of natural history, they will not, perhaps, be unacceptable to this honourable and learned Society.

There can be no doubt that the production of saltpetre or nitre, in the situations above alluded to, had been obscrved long before there existed any general inducement to collect it from those sources; but after the invention and stbsequent extensive employment of gunpowder, it became an object not only to search out every natural source of the principal ingredient of that important compound, but also to investigate the circumstances of its production; for the purpose either of accelerating the natural process, or of imitating it by artificial means.

The usual and almost exclusive occurrence of saltpetre on walls constructed of limestone, and in situations exposed to animal and vegetable effluvia, in all probability led to the empirical practice of heaping together the mortar and refuse of old build-

* From the Philosophical Transactions for 1814, part ii.

1. Saltpetre (Sa! Petra.) 
ings with putrescent animal and vegetable matter; from a mixture of which kind, after exposure for a sufficient length of time to the action of the air, a quantity of nitre may usually be obtained by lixiviation: but it would be a question of mere curiosity, on this occasion at least, to investigate the origin of the practice. The intention of the present paper is to state the result of a series of observations made during the last year, on the connexion that exists between the natural production of nitre and the state of the atmosphere. In detailing these observations, it will be convenient to give previously a description of the laboratory of the Ashmole Museum, in which building they were principaliy made: nor shall I be afraid of being thought too minute in this description, or in any other part of the following detail, by those at least who know the precision that is requisite in every induction, which like the present rests on phænomena of an obscure and equivocal nature.

The Ashmole Museum, which was built by Sir $\mathrm{C}$. Wren in the reign of Charles the Second, is an insulated building, constructed entirely of calcareous freestone, and consisting of three stories. The lowermost of these stories was originally designed for, and has constantly been used as, a chemical laboratory.

The pavement of the laborntory, on its eastern. northern, and western sides, is about nine feet below the level of the street in which the Museum stands; on its southern side it is on the same level with an area, about ten feet in breadth, which in part occupies the site of the ditch of the old town, and insulates a quadrangular projecting part of the whole building of the Museum. The laboratory itself is a single room sixty feet in length from east to west, and twenty-five in breadth; having an arched stone ceiling, the centre of which is seventeen feet above the level of the pavement. The walls of this room, which are ncarly three feet in thickness, are constructed of squared calcareous freestone, which I have reason to believe was dug from a quarry near Burford, and is technically called Windrush stone, from the river of the same name. There are four windows in the upper part of the north side of the laboratory, formed in the curve of the arched ceiling; the dimensions of each of which are five feet by four and a half.

There is no window either on the eastern or western side of the laboratory.

On the south side there are two windows, one at each extremity, looking into the area above described; and these windows are placed at the usual distance from the ground, that is, aljout three feet: and all that part of the south side intermediate to these two windows separates the laboratory from the 
quadrangular projecting part of the whole building of the Museum aliendy mentioned.

The saline efforescence takes place most copiously on the north wall, and it occurs on various parts of it from narly the level of the pavement to within three or four feet of the centre of the arched ceiling. It takes place also, though not so abundantly, on the east and west walls; and also at the eastern and western extremity of the south wall; but it is worth noticing, that I have never seen it on that part of the south wall which is common to the laboratory and the attached projecting building of the Museum. It is true that there are chimneys in this wall connected with fires that are lighted daily; but this circumstance does not seem suflicient to account for the absence of the nitre, because its formation takes place in another part of the laboratory equally near a chimney, and in which, from being inclosed, the temperature of the air is always considerably higher.

It is also worth noticing, that between the lighest and lowest points of its appearance in every part of the building there are intercepted spaces entirely and always free from the least deposition.

I may here mention that the occasional formation of nitre is observable in many other buildings and parts of Oxford, besides the laboratory of the Ashmole Museum; as on the wall, called Long Wall, which bounds the park of Magdalene College to the west-on the exterior surface of the south wall of the Theatreon the exterior surface of the three walls of the yuadrangular projecting part of the Ashmole Museum-very abundantiv on the inclined base of the windows of the Examination Schoo?, looking to the north-and also very abundantly on the west side of the wall, which separates the square of the Schools from the arched way leading from thence to the Theatre and Convocation House.

It has been observed repeatedly, that the presence of lime is necessary to the natural production of saltpetre; and in all the foregroing instances the stone on which the saline cfilorescence takes place is the common limestone of Oxfordshire. I have only once observed its formation on the surface of a brick wall : but in that instance the substance of those bricks on which the nitre appeared had crumbled awny to some depth; and if this destruction of thcir texture be owing to the presence of an unusual proportion of lime in the clay of which they are made, (a supposition not improbable, since many parts of the stratim of clay from which bricks in this neighbourhood are made do contain an unusual proportion of lime), the reason of the exception in the case of this brick wall will correspond with the truth of the general observation above stated.

Vol.44. No.200. Dcc.1814. D d The 
The following circumstance is particularly leserving of notice. A part of the north wall of the laboratory, on which saltpetre usually effloresced, having been covered with wainscut some monthis since, and the wainsent having been painted with common white paint, I was surprised after a time in observing an efflorescence on particular parts of the paint, similar to what might have been expected on the wall itself. Where this efflorescence had taken place the paint was loosened from the wainseot, and might he rearlily peeled off in small flakes. The saline particles of which this efflorescence consisted I at first sipposed to be nitrate of lead; but upon examination in varions ways no trace of lead could be found in them, and they exhibited the principal characters of common nitre : they deflagrated, for instance, with charcoal, leaving a deliquescent alkaline residuum. Many weeks have elapsed since that saline efflorescence was brushed off, but I have not yet observed any renewal of it.

Though the production of saltpetre had been pointed out to me in the laboratory of the Ashmole Museum as long since as the year 1802 , I was prevented by many circumstances from observing with any degree of regularity or precision the phenomena of this natural process previously to the commencement of last year; about which time having carefully brushed away the whole of the saline eflorescence from a part of the north wall situated below the level of the street, and very imperfectly exposed to the light, I was surprised by the fact of its quick reappearance. It was brushed away at the end of January; but within three days it had again effloresced in sufficient quantity to present that appearance of hoar frost, or down, or mould, which is very characteristic of the manner in which naturally formed saltpetre is often accumulated; and which a person, utterly incapable of judging of the real nature of the substance, described at the time by the term "damp."

I was still more surprised, however, in observing after a few days, that the quantity of the saltpetre was apparently very much diminished; and that at the end of eight or ten days there was scarcely any appearance of it remaining: though there was no reason to suppose a particle had either aceidentally fallen to the ground or been intentionally removed.

The same part of the wall was again brushed perfectly clean, and I continued to make daily observations in expectation of a renewal of the process; but no new collection was perceptible, excepting in the form of a very few detached and minute capilJary crystals, till the 16 th of March; on which day, having been absent diring the whole of the 14 th and 15 th, I found a more abundant accumulation than in the preceding instances. 
It was an obvious supposition that the reproduction of the nitre was connected with some cliange in the state of the atmosphere: and it is to be remarked, that its first-mentioned appearance took place in frosty weather, and that its reappearance about the $16 \mathrm{th}$ of March hav been preceded by a frost of a few days; whereas during the intervals in which it disappeared and was not again produced, the weather had been mild. The wall was again brished quite clean on the 16 th of March; between which day and the fth of $A_{\text {pril a }}$ considerable cuantity had again collected on the same part ; the process having been more rapid during the last four or tive days, which were cold.

On April the 12th the front of this part of the wall was renewed by scraping, for the purpose of observing what would be the effect of a fresh surface, and before the 25, th of $A$ pril nitre had formed on many parts of this new surface ; bit having first increased and then continued stationary for some days, it began to diminish about the beginring of May, the state of the air having been very moist during the two or three preceding days.

About the middle of May 1813 I selected several distinct parts on which the spontaneous formation of nitre vsually takes place, some within and some without the building of the Museum, and began to make daily observations on the phænomena of that process, which I noted down at the time: bat as a register of this kind would be unnecessarily tedious in its recital, I shall beg leave to give the following general results of those observations; requesting it may be kept in mind, that I do not presume to lay a greater stress on them than is proportional to the short period of time and the circumscribed space in which they were made.

It appears then from the observations I have hitherto been able to make, that the spontaneous formation of saltyetre is, generally speaking, much more extensive and rapid in winter than in summer, whether it take place on the interior or exterior of a builling: thus during the period of the cold weather in Jamuary 1S1, it bacane visible not only on parts of the walls where I had never before observed it, but eveil on the pavement of the laboratory. The part of the pavenent on which it appened is adjacent to the north wall ; but as the greater part of the pavement is covered by a flooring of wood, it is impossible to say whether or not it took place on other parts also. The stone forming the pavement is the same kind of limestone as that of which the walls are built.

Again, whereas in summer its reproduction is most rapid and extensive in proportion to the degree of light present, the reverse of this (though not universally) takes place in winter. Wherever the saline efllorescence in question occurs, the sur$\mathrm{D} \mathrm{d} 2$ 
face of the stone becomes permanently discoloured, as if from the effect of damp; but this discoloration is merely superficial. If these discoloured parts be whitcwashed, the process still goes on ; and the whitewash is gradually detached in flakes: but it is dificult to ascertain whether the nitre is formed on the whitewash, or on the wall which it covers; though probably the latter.

When the spontaneous formation of nitre takes place slowly and in a sheltered situation, it is at first visible in the form of minute prismatic crystals, which usually project from the surface of the wall nearly at right angles; but sometimes they are scattered in different directions, lying upon its surface so lightly as scarcely to appear in contact with it. In general, however, the saline efflorescence makes its appearance in extremely minute capillary crystals, either accumulated in groups, which resemble recently fallen flakes of snow, or investing the wall like a fine down.

During the severely cold weather of January 1814, it appeared in some places in the form of minute dense grains closely aggregated; while in others it still continued to wear the appearance of down or wool: and the local circumstances most obviously connected with this difference in the manner of crystallization, were the presence of a greater degree of light, where the granular deposition took place, and a less degree of shelter from the influence of cold air.

In some instances the production of the saltpetre is accompanied with a disintegration of the substance of the stone on which it is formed : but this circumstance is only observable on stones of a loose texture.

The shortest interval I have observed between the time of its having been brushed away and its reappearance, is four hours : but it was then in full efflorescence, and would probably have been visible much earlier. 'The observation was made on $\mathrm{No}-$ vember the 17 th, about midnight: there had been snow in the midle of the day, and the night was frosty.

The spontaneous formation of nitre takes place indifferently on the surface of the stones composing a wall, and of the mortar by which those stones are cemented; and near the close of the late frost, I observed it for the first time on the surface of a partition consisting entirely of laths plastered over with the mortar or stucco commonly used for that purpose.

It accumulates in greater quantity on some parts of a given surface than on others; and this difference in the degree of its accumulation, is probably connected with some slight difference in the texture or composition of the stone on which it is formed: for I have repeatedly observed that after a careful removal of it, 
its reproduction takes place to the same proportional extent in the same parts: and this difference in the degree of the cfllorescence often takes place not by a gradual transition, but as abruptly as if the line of separation had been marked by a graver; so that the part of the surface on one side of the line shall be almost totally devoid of any efflorescence, while on the other side it shall resemble the accumulation of hoar-frost on the small branches of a tree.

The saltpetre formed in summer scurcaly appears to contain a particle of any calcareous salt: that formed in winter continin most evident traces of such a salt, though probahly even in winter the amount of this is not much above one part in two hundred of the whole mass.

A frosty, clear, and dry state of the atmosphere is particularly favourable to the natural production of nitre: but there seems to be a limit to its formation, on the sime spot, even under the most favourable circumstances; the guntity of the nitre not continumg to increase after it has proceded to a certain extent.

In a moist state of the atmosphere the formation either does not take place at all, or goes on slowly : and if that state of the atmosphere which is unfavourable to the production of nitre continue a sufficient length of time, the nitre already formed gradually disappears. At the commeneement of these observations I attributed the uccasional disappearance of the nitre to its mechanical removal from the wall, and supposed that it must have been by accident brushed off : but repeated observations convinced me this was not the case, its disappearance procecding as gradually as its previous appearance; besides which, had it fallen from the wall, I should most probably have found it on the pavement beneath, which never happened to me. It afterwards appeared probable, although I have never met with any condensed moisture on the surfaces submitted to the foregoing observations, that the aqueous vapour precipitated from the atmosphere in the state of it above alluded to, might dissolve minute particles of the nitre, and be absorbed with them into the substance of the wall ; but on this supposition nitre ought to be found in lixiviating a portion of the stone taken near the surface. I have however made the experiment without detecting any nitre in the stone so taken. But, in opposition to the idea of the absorption of the nitre into the substance of the stone, I found the efforescence disappear in more places than one during the severe frost of the present year (1814), at a time when, from the temperature of the stone, if not of the air also, the absorption here supposed could not have taken place; since, that temperaturc being below the freezing point, the aqueous particles $D$ d 3 
would by congelation have been rendered incapable of dissolving the nitre.

It is deserving of notice, that such a spontaneous disappearance of the nitre, as has been just mentioned, took place anteredontly to and during the late heavy fall of snow on January Is andig.

Wishing to ascertain whether the free presence of atmosphericul air be necessary in the natural process under consideration, $i$ selected a part of the wall on which the formation if saltpetre usually takes place to a considerable extent; and insulated about a square foot of its surface which had been previously brushed quite clean. It was insulated by means of a plate of glass, the edges of the frame of which were covered with a cement, so as to exclude any access of air between the glass aud the wall. As the depth of the frame was not more than the third of an inch, the inclosed space contained but an inconsiderat?le guantity of atmospherical air. On the following day, October 29, I observed that a formation of nitre had taken place on the part of the wall within the glass, but that it was not so extensively diffused, nor so abundantly deposited, as had been usual before the application of the glass; and the crystals, which were distinctly prismatic, were much more accurately defined, and larger, than I had ever before observed them; in consequence, probably, of the tranquil state of the medium in which they were formed. On the day following, October 30 , the quantity was increased; hut it remaincd stationary from that time to November 12, when it began to diminish ; and on November 16 there was no longer any appearance of it : nor did it reappear in the interval between November 16 and 29 . In the mean time the efflorescence had not only taken place on the adjacent parts of the wall in the usual manner, but had been more than once brushed off and again deposited, while no increase had taken place in that originally formed within the glass.

On November 29, the exterior surface of the glass was, for a purpose to be mentioned presently, covered over with whitewash; which was not removed till January 8,1814 . No observation could of course be made on the appearance of the surface within the glass during the interval that the glass itself was covered with whitewsh ; but no nitre was visible on the removal of the whitewash on Jamuary S. It had, however, reappeared before the morning of January 10 , partly in separate capillary prismatic crystals which were much larger than on the former occasion, and reached from the stirface of the wall to the inner surface of the glass; and partly in small ficeculent tufts; the whole quantity of the nitre formed being much greater than, and the maniner of its formation being very different from, that formation which 
which took place within the glass on October 29 and 30 . Still the whole quantity was not nearly equal to that which waw unally formed on the sane surfice when exponed to the free action of the atmosphere. The increased quantity howerer formed in January, compared with that formed in October, conesponds with the observation that the natual production of sitre is much influenced by temperature: but it is worth mentioning, that while the nitre formed within the glass in January occurred cither in distinctly prismatic crystals or in flicculent tuft:, that which was formed on the adjacent parts of the wall was of the granthar character above described in page 120 .

Having by the foregoing experiment satisfed mycelf with respect to the necessity of the free presence of atmospherical air for the full effect in the spontaneous prosiction of nitre, I wished to ascertain the nature of the comexion between the nitre formed and the stone on which it is formed; and particularly whether carbonate of lime simply would be suficient for its production. I therefore made a nearly lichuid paste with distilled water and prepared chalk *, with which I covered the exterior surface of the glass that had been attached to the wall for the purpose already mentioned: but though nitre was repeatedly formed in the neighbourhood of the glass, not a particle appeared on the whitewash during the space of nearly six weeks, from November 29 to January 8 .

The foregoing statement contains the general results of all the observations I have hitherto been able to make on the present subject. I subjoin an imperfect analysis of the stone of which the laboratory of the Asmole Museum is built, and of the saltpetre periodically formed on it ; concluding with a few remarks on the local differences connected with a more or less extensive formation of that substance, and on its jrobable or rather possible source.

The stone of which the laboratory is constructed belongs to one of those alternating series of clay, and sand, and calcareous freestone, of which the varieties of Bath stone form nearly the lowermost strata; and the Headington stone, of which the greater part of Oxford is built, the uppermost. It is principally made up of the detris of small sea shells, but frequently contains organic vegetable remains, and always some proportion of sand and ochry clay.

Six portions of this stone taken from different parts of the labo-

* As chalk sometimes contains magnesia, and almost always a snatl proportion of silex and aluminc, 1 inteid on a future occasion to repeat the experinent, using very finely pulverized crystallized calcarcous spar, instead of chalk. 
ratory, each weighing at least two hundred grains, were separately submitted to the action of a sufficient quantity of diluted muriatic acid. The undissolved residuum, which amounted in no instance to as much as four parts in a hundred, consisted of a yellowish browu ochry clay, mised with a few particles of white sand, and small laminar fragnents of a dirty-white colour, very much resembling portions of the siliceous incrustation of the Geyser spring. Small flocculent shreds slowly subsided in the muriatic solntion, derived probably from the membranons part of the shelly inntter of the limestone; for this insoluble residuum, when thrown into red-hot nitre, slighthly deflagrated, and gave out an odour resenbling burnt bones: and as this residuum had been collected without the use of a tilter, the inflammable matter conld not well have been derived from any other source than the stone itself.

The muriatic solution contained a small proportion of iron, and gave a very slight trace of magnesia. So that the composition of the stone may be thus stated:

Carbonate of lime $\ldots \ldots \ldots \ldots \ldots \ldots \ldots \ldots . \ldots 96$

Oxide of iron, sand, ochry clay, and animal membrane.. 4

100

In offering the following imperfect analysis of the saltpetre prorluced in the situations above alluded to, it is necessary to state, that the quantities on which I have hitherto had it in my power to operate have been very small.

Some preliminary experiments nade on a solution of saltpetre which hat been formed during the summer, gave the following results.

The solation contaiued no disengaged acid or alkali, and apon the addition of oxalate of ammonia afforded the slightest possible evidence of the presence of lime. It contained minute portions of sulphuric and muriatic acid. $\Lambda$ portion of it being evaporated left a mass of crystals which, in their form, as in ill their other characiers, exlibited the properties of nitrate of potasin.

As it is usually stated by writers who speak of the subject, tlat nitrate of line is a principal constituent part of saltpetre formed by a natural process, I was much surprised by the very slight trace of lime cvident in the present instance; though I hud folt assured previously that but little would be found in the natural saltpetre which I have had an opportunity of examining; having never observed in it any tendency towards deliquescence. Having had frequent occasion to sappose that carbonate of lime is much more readily soluble in water than is commonly befieved, and having never been able to detach the saline effiores- 
cence in question from the walls of the laboratory, \&c. without admixture of particles of the limestone, or of the whitewash, amounting to at least seven or eight parts in a hundred, it struck me that these particles might be the source of the lime rendered evident by the addition of the oxalate of ammonia in the solution of the saltpetre. I therefore pulverised small portions of calcareous spar, of the common limestone of this country, and of whitewash; and having agitated accurately distilled water, at the common temperature, with each of these portions, I then filtered the water, and tested it with oxalate of ammonia. In each instance there was fully as copions a precipitate as when the oxalate of ammonia had been added to an equal quantity of the solution of saltpetre.

Similar preliminary experiments having been made on some saltpetre detached from the same part with that already submitted to examination, but formed during the winter instead of the summer, the same results were obtained, with this single difference, that the precipitate obtained by the addition of oxalate of ammonia was much more copjious: and I found this to be the case from whatever part of the laboratory or elsewhere the saltpetre had been detached, provided it had seen formed during the winter. I could not extend the experiment on the saltpetre formed during the summer, having only reserved a portion from one spot.

Judging from such experiments as I have made, it appears that the saltpetre formed in the situations described in this paper consists of full 99 parts in 100 of nitrate of potasl: ; with a verv minute proportion of some calcareons salt, which is either not at all present in in the saltpetre formed during summer, or is present in smaller quantity than in that formed during winterthough even in the latter instance it scarcely amounts to one part in 200.

The proportion of sulphuric and of muriatic acid, and the bases with which these acids are combined, I have not attempted to ascertain, on aceount of the minuteness of the proportion in which they evidently exist.

In considering the relative situations of the different parts of the laboratory, and the other buildings also, in which saltpetre is naturally formed, it is evident that the efflorescence takes place only where the exterior of the wall on which it is formed is either exposed to the direct influence of the weather, or is in contact with the adjacent ground; not taking place at all in those instances in which the wall is neither exposed to the weather on either side, nor is in contact with the adjacent ground: from which it might be argued, that the effect depends upon the 


\section{OtsGrvations on the natural Production of Sallpetre.}

action of the external air, or of the moistume of the ground transmitted through the substance of the wall; but the result of that experiment in which, the action of the air on the interior surface of the wall having been prevented by the intervention of a glass, the formation of nitre took place only to a very slight extent, is in a great measure at variance with such a supposition.

Again : though it is evident that the natural production of the saltipetre is closely connected with changes in the state of the atmosplinere, those changes relating not only to its temperature but abo to the degree of its moisture and barometrical pressure; ret a much longer series of observations, and these not partial like the present, but carried on in various parts of the world, is requisite, before even this part of the problen can be accurately solved. There still would remain a part of much more difficult solution, namely, the source of the metallic base of the alkali of the nitre.

With respect to this difficult question, if we compare the cléments present in the composition of the saltpetre formed, with the elements of the substances present during its formation, it seems a reasonable conclusion that the potassium, or the metallie bae of the potash of the saltpetre, is either a simple principle of some of the elcinents present, or that it results from the union of two or more of those principles, or of two or more of the elements themselves*.

The gross compounds present during the formation of saltpetre, in the instances mentioned in this paper, are atmospherical air and the limestone on which the saltpetre effloresces; and all the component parts of these may be ultimately resolved into the following elements-oxygen, nitrogen, hydrogen, and carbon, together with iron and the metallic bases of some of the earths.

The component parts of nitrate of potash, of which the saltpetre under comideration almost entirely consists, are nitric acid, water, and potash; which may be resolved into the following elements-oxygen, nitrogen, hydrogen, and potassium: and all these elements are experimentally known to be present in the situations where saltpetre is formed, with the exception of potassium.

In the supposition then that the saltpetre is a product and not an educt of the above process, since no potash can be de-

* The terms "elcment" and "principle" are here used in the same reJation to cach other as the early physical philosopher's used the terms ororcise aezeri. 'litey supposed that the firner, though incapable of decomposition riy common neano, nere not necessurily to be cussitered as absolutely simple sulsctances: thuse absolutely simple substances tiley expresser by fhe term $\alpha_{3}^{3} x x^{2}$. 
tected either in the air or limestone, the potassium must cither be contained in a free state in the atmosphere or in the limestone, which from its remarkable attraction for oxygen is inatmiscible: or it must be a component principle of some one of the elements present ; or lastly, it must be itself a compound of two or more of the principles of those elements, or of two or more of the elements themselves.

But I am aware that the saltpetre may be considered as an educt of the process, and that it may possibly exist already formed in the atmosphere in a state of minute division: yet, when we consider the comparatively fixed nature of that salt, and that no experiments have yet detected its presence in atmospherical air, or in the moisture precipitated from atmospherical air; and lastly, when we reflect on the probability that the metals, of which potassium is one, are compound bodies, the former supposition seems upon the whole pieferable to the latter.

Felistiary, 181.

\section{Stratification of Glamorganshire*.}

\section{Mountain Lime.}

Trs HIs rock forms the whole of the peninsula of Gower, westward of a line drawn S.S.E. through Penclawold, Gellyhir, Littlehills, west side of Clgne Moor to Blackpill ; appears again near Pgle Inu, Centig, Skerr, Cornoly, Sottage, Nexton Down, Cevn Cribhor, rises through the lias at Ewenny, forms Ewenny and Ogmore Downs, Golden Milk, Saint Mary Hill, Coed y Mwstor near Coychurch, Newforest, Llanblethian, Penlline, Trecastle, Lanchacar, Stalling Down near Cowbridge, Saint Lythians Down, Currtgrala, Bolston, covered hy alluvia at St. George's and elsewhere in that valley. Very hard variety at Saint Fagaas. Hills ne:ar Lantrissant E. and W. Lower Garth, Castell Coch, Lisvane towards Caephilly, Ruddrey, whence at Machen it runs into Monmouthshire. This last named range bounds the great coal basin which will be presently described. I have observed no fossil madrepores, but abundance of entrochi ; galena is found in various places. A shallow bed of coarse sandstone rests on the mountain lime at St. Hilary and Lantrythid; berls of white calcareous slate have been cut through in the lead mines there. Manganese has been worked on Newton Down. Cherty blocks may be observed there and on St. Mary Hill.-

* For the localities mentioned in this sketch, see the excellent Map of Glamorganshire, published from the Survey of G. Xates, by Cary, 181, Strand, London. 